\title{
Effects of inulin on faecal bifidobacteria in human subjects
}

\author{
Hans-P. Kruse ${ }^{1 *}$, Brigitta Kleessen ${ }^{2}$ and Michael Blaut ${ }^{2}$ \\ ${ }^{1}$ University of Potsdam, Institute of Nutritional Science, Arthur-Scheunert-Allee 114-116, D-14558 Bergholz-Rehbruecke, \\ Germany \\ ${ }^{2}$ German Institute of Human Nutrition Potsdam-Rehbruecke, Arthur-Scheunert-Allee 114-116, \\ D-14558 Bergholz-Rehbruecke, Germany
}

(Received 23 November 1998 - Revised 6 April 1999 - Accepted 18 May 1999)

\begin{abstract}
A controlled study with eight healthy free-living subjects was carried out, in which energy intake was adjusted to the individual energy requirements. On administration of inulin, blood lipids, the faecal microflora, short-chain fatty acids and accompanying gastrointestinal symptoms were characterized in order to investigate the long-term effect of inulin. During the run-in phase ( $8 \mathrm{~d})$, subjects received a typical Western diet providing $45 \%$ energy as fat and $40 \%$ energy as carbohydrate. Subsequently, the subjects consumed a fat-reduced diet which provided $30 \%$ energy as fat and $55 \%$ energy as carbohydrate for a period of $64 \mathrm{~d}$ using inulin as a fat replacer. The amounts of inulin consumed by the subjects (up to $34 \mathrm{~g} / \mathrm{d}$ ) were based on individual energy requirements with the aim to keep the diet isoenergetic with that used in the run-in period. To assess the effects of inulin administration, a control study (run-in and intervention) was carried out in which subjects consumed the same diet but devoid of inulin during the whole course of the study. To investigate the effect of inulin on faecal flora composition total bacteria and bifidobacteria in the faeces were enumerated by in situ hybridization with 16S rRNA targeted oligonucleotide probes. Inulin significantly increased bifidobacteria from 9.8 to $11.0 \log _{10} / \mathrm{g}$ dry faeces and caused a moderate increase in gastrointestinal symptoms such as flatulence and bloatedness, whereas blood lipids and short-chain fatty acids remained essentially unaffected.
\end{abstract}

Inulin: Blood lipids: Bifidobacteria

In contemporary Western societies the lifestyle is characterized by a high dietary energy input due to a surplus of alimentary fat and reduced physical activity, leading to an increased incidence of adiposity. To meet dietary guidelines aimed at lowering fat consumption to prevent overweight and, at the same time, satisfying the consumer's enjoyment, the food industry has developed low-fat products using fat replacers. Such a fat replacer is inulin from chicory (Cichorium intybus) roots or Jerusalem artichoke (Helianthus tuberosus), which may help to improve the acceptability of low-fat food products by the consumer while also contributing to decreases in energy intake and body weight (Dreon et al. 1988; Grundy, 1991; Bruhn et al. 1992; Hautvast, 1992; Klesges et al. 1992; Watts et al. 1992; Silva, 1996).

Interest in inulin for human nutrition originates also from its fibre nature. Since inulin is not degraded by human intestinal enzymes, it reaches the colon where it undergoes almost complete fermentation by the colonic microflora (Roberfroid, 1993). Previous studies have demonstrated that inulin and fructooligosaccharides selectively stimulate the growth of bifidobacteria in the colon (Gibson et al. 1995; Gibson \& Roberfroid, 1995; Kleessen et al. 1997; Roberfroid et al. 1998). Moreover, it has been shown that the fermentation in the colon may favour the formation of shortchain fatty acids (SCFA) such as acetate, propionate and butyrate. Since butyrate is the preferred energy substrate for colonocytes (Roediger, 1980; Cummings, 1981; Cummings \& MacFarlane, 1997) the microbial formation of SCFA has an impact on the mucosa (Scheppach, 1994).

The purpose of the present study was to evaluate inulin under free-living conditions in an energy-controlled fatreduced dietary programme over a period of 10 weeks with respect to gastrointestinal compatibility and effects on faecal microflora, SCFA and blood lipid variables.

\section{Materials and methods}

\section{Materials}

The inulin (FIBRULINE ${ }^{\circledR}$ ) was obtained from Cosucra s.a., Fontenoy, Belgium. The polymer, which is extracted from 
chicory roots ranges in a degree of polymerization from 2 to 50 and has an average degree of polymerization of 9 .

\section{Subjects}

Eleven healthy subjects, five female and six male individuals, aged 26-53 years, were recruited from the staff of the institute. They were free of any medication. Blood lipid variables of all subjects were in the normal range. The mean BMI of the females and males were 22.8 (SD 4.4) and 25.8 (SD 1.6$) \mathrm{kg} / \mathrm{m}^{2}$ respectively. Informed consent was obtained from all subjects after the experimental procedures had been explained. The protocol for the study was approved by the Ethical Committee of Brandenburg.

\section{Experimental design}

For a period of $8 \mathrm{~d}$ (run-in) volunteers consumed a typical Western diet composed in such a way that fat, carbohydrates and protein contributed 45,40 and $15 \%$ respectively to the individual maintenance energy requirements. The specific energy requirement of each volunteer was calculated on the basis of prior measurements of the resting metabolic rate (RMR) to which $13 \%$ RMR was added for thermogenesis and 26\% RMR for slight physical activity (free-time and job as 26\% RMR) (World Health Organization, 1985; Steiniger et al. 1987).

Using a calculation software program (DGE-PC version 1a; GiVmbH, Goettingen, Germany) dishes were composed to meet the individual maintenance energy requirements and distributed by the institute's canteen. Foods typically found in everyday diets were prepared to simulate normal life conditions. Of the individual energy requirements $26 \%$ and $30 \%$ were consumed at breakfast and the main meal respectively. These portions of energy corresponded to the size of meal usually eaten by the subjects. The composition of breakfast was constant over the whole study. The main meal was changed daily depending on the canteen's offer, but all subjects had the same diet, differing only in size according to the individual energy requirements. The participants in the study had supper at home. They were instructed to continue their normal life habits but to keep the diet on the given macronutrient ratio. The agreement with these instructions was controlled daily by detailed nutrition reports on a weight basis and, if necessary, corrected.

Following the run-in period, the diet was changed for a period of $64 \mathrm{~d}$. In this experimental phase $30 \%$ total energy was provided by fat, $55 \%$ by carbohydrates and $15 \%$ by protein. However, the diet was isoenergetic with that of the run-in phase. Typically, food items rich in carbohydrate were consumed and inulin was used as a fat replacer. Depending on the individual energy requirements of the subjects, the amounts of inulin administered ranged from 22 to $34 \mathrm{~g}$ daily. Since the energy value of inulin is about $4 \mathrm{~kJ} / \mathrm{g}$ (Roberfroid et al. 1993), the amount of inulin consumed corresponded only to $25 \%$ of the energy coming from carbohydrates which were used to compensate the fat energy due to dietary fat reduction from 45 to $30 \%$ in this phase of the study. The individually calculated inulin load was consumed entirely through commercially available yoghurt at breakfast.
The main meal and supper were changed in such a way that the proportions of carbohydrates were also increased to meet the macronutrient ratio by energy. Again, the nutrition scheme was controlled daily and corrected if required.

Following their usual habits, subjects had either tea or coffee for breakfast throughout the whole study in the same manner. Except at weekends, breakfast and main course were always served at 08.15 hours and 12.30 hours respectively.

As a control the study described was repeated with the same subjects but without inulin. Within the intervention phase the energy replacement of fat by carbohydrates was accomplished by offering higher proportions of rice, potatoes or bread.

\section{Sampling}

Blood. In the course of the study, three blood samples were taken from each subject in the early morning: at the end of the run-in period (day 8), in the middle of the intervention phase (day 27) and at the end of the intervention phase (day 64). Subjects fasted overnight and the last meal was at least $12 \mathrm{~h}$ before sampling. Blood cells were removed by centrifugation and the serum was analysed immediately.

Stool. Stool samples were collected at the end of the run-in phase (day 8), in the middle (day 27) and at the end of the intervention phase (day 62), and $34 \mathrm{~d}$ following the end of the study. For microbiological enumeration $0.5 \mathrm{~g}$ specimen was processed immediately. Portions were dried for estimation of DM. For analysing SCFA, samples were frozen and stored at $-20^{\circ}$. At 2 weeks following the end of the study the samples were thawed and prepared for GC analysis.

\section{Analytical}

Blood lipids. Total serum cholesterol and triacylglycerols were determined spectrophotometrically with commercial test kits Cholesterol Unimate 5 and Triglyceride GPO Unimate 5 (Roche, Grenzach-Wyhlen, Germany) on an autoanalyser Cobas Mira S (Hoffmann-La Roche, Basel, Switzerland) according to the instructions of the manufacturer. HDL and LDL were determined in the same way as total cholesterol but after previous precipitation by means of phosphotungstic acid- $\mathrm{MgCl}_{2}$ and polyvinylsulfate respectively.

Microbiological studies. Total bacteria and bifidobacteria in the faeces were enumerated by in situ identification using the following 16S rRNA targeted oligonucleotide probes $\left(5^{\prime}\right.$ labelled with the indocarbocyanine dye $\mathrm{Cy} 3$; Biometra, Göttingen, Germany): (1) an equimolar mixture of five bacteria-directed probes EUB 338, EUB 785, EUB 927, EUB 1055, EUB 1088 (Amann et al. 1995), referred to as EUB mix, to detect all bacteria, and (2) BIF 164 to detect bifidobacteria (Langendijk et al. 1995). Freshly voided faeces $(0.5 \mathrm{~g})$ were homogenized in $4.5 \mathrm{ml}$ sterile PBS $(130 \mathrm{mM}-$ $\mathrm{NaCl}, 10 \mathrm{mM}-\mathrm{Na}_{2} \mathrm{HPO}_{4} / \mathrm{NaH}_{2} \mathrm{PO}_{4}, \mathrm{pH} 7.4$ ), fixed in three volumes fresh $40 \mathrm{~g} / \mathrm{l}$ paraformaldehyde-PBS for $3 \mathrm{~h}$, washed once in PBS and resuspended in a 1:1 mixture of PBS and $960 \mathrm{ml} / \mathrm{l}$ ethanol. For fixation of bifidobacteria the faecal 
suspension was mixed with an equal volume of ice-cold ethanol. All samples were stored at $-20^{\circ}$ and processed within $10 \mathrm{~d}$.

In situ hybridization was essentially done as described by Manz et al. (1993). For homogenization fixed samples were treated for $4 \mathrm{~min}$ in a Uniprep-Gyrator (InViTek $\mathrm{mbH}$, Berlin, Germany) and spotted on 3-aminopropyltriethoxysilane (APES)-coated slides (20 g APES/l in $990 \mathrm{ml} / \mathrm{l}$ methanol), and allowed to air-dry. Fixed cells were hybridized for $16 \mathrm{~h}$ at $46^{\circ}$ in $50 \mu \mathrm{l}$ hybridization buffer $(0 \cdot 9 \mathrm{M} \mathrm{NaCl}, 0 \cdot 1 \mathrm{~g} / 1$ SDS and $10 \mathrm{~mm}$ Tris/HCl, $\mathrm{pH} 7.4$ ) containing $5 \mathrm{ng}$ probe/ $\mu \mathrm{l}$. After hybridization the slides were washed in hybridization buffer for $20 \mathrm{~min}$ at $48^{\circ}$ and were examined with an Optiphot-2 epifluorescence microscope (Nikon, Düsseldorf, Germany) equipped with a $100 \times 1.30$ Plan Neofluor Ph4 oil immersion objective, an HBO $100 \mathrm{~W} / 2 \mathrm{Hg}$ lamp, and the filter block G-2A. All samples were counted in duplicate using a net micrometer (twenty-five assays with $\geqslant 120$ cells per assay). The microbial counts are expressed as $\log _{10}$ organisms/g dry faeces.

Short-chain fatty acids. Faecal SCFA were quantified as previously described by Pomare et al. (1985) and Scheppach et al. $(1987,1989)$ with modifications.

Sample preparation: samples were homogenized with distilled water $(1: 5 \mathrm{w} / \mathrm{v})$ using ultrasound and centrifuged at $15000 \mathrm{rev} / \mathrm{min}$ for $5 \mathrm{~min}$. A portion $(100 \mu \mathrm{l})$ of the supernatant fraction was acidified with $280 \mu \mathrm{l} \mathrm{HClO}_{4}$ $(0.36 \mathrm{M})$ and $23.6 \mu \mathrm{l}$ i-butyric acid $(12 \mathrm{mM})$ as an internal standard; subsequently, $270 \mu \mathrm{l} \mathrm{NaOH}(1 \mathrm{M})$ was added. The samples were thoroughly mixed, frozen in liquid $\mathrm{N}_{2}$, lyophilized, acidified with $100 \mu$ l formic acid (5 M), mixed with $400 \mu l$ acetone and thoroughly vortex-mixed. Subsequently, the supernatant fraction was transferred into a vial and analysed automatically by GC. Two parallel preparations were analysed.

GC: concentrations of SCFA were determined using an HP 5890 II GC (Hewlett-Packard GmbH, Waldbronn, Germany) fitted with a capillary column coated with acid-modified PEG (EC-1000: $30 \mathrm{~m} \times 0.32 \mathrm{~mm} \times 0.25 \mu \mathrm{m}$; split: 1:4; flameionization detection; injection volume: $1 \mu \mathrm{l})$. He gas was used as the carrier at a flow rate of $1.7 \mathrm{ml} / \mathrm{min}$. Oven temperature was held initially at $90^{\circ}$ for $2 \mathrm{~min}$ and programmed to increase subsequently at a rate of $10^{\circ} / \mathrm{min}$ to $190^{\circ}$. The temperature of both the detector and injector was $250^{\circ}$.

Resting metabolic rate. For the determination of RMR concentrations of $\mathrm{O}_{2}$ and $\mathrm{CO}_{2}$ of fasting subjects were measured early in the morning using Sensor Medics 2900 (NewMedics, Öhringen, Germany) equipped with a respiratory mask. Data were collected over a period of $2 \mathrm{~h}$ and eight measurements (each for a period of $5 \mathrm{~min}$ ) were averaged. The RMR was calculated from the total $\mathrm{O}_{2}$ consumption and the $\mathrm{CO}_{2}$ production according to the method of Erbersdobler et al. (1976).

Assessment of gastrointestinal symptoms. Gastrointestinal signals of inulin administration were assessed according to van Munster et al. (1994) and Pedersen et al. (1997). At the end of the run-in and the intervention phases, subjects were asked to express their complaints experienced during the study. A list of eleven possible symptoms such as nausea, vomiting, belching, acid reflux, bloatedness, flatulence, diarrhoea, rumbling stomach, rumbling gut, cramps of stomach as well as gut cramps could be selected as being absent (0), mild (1), moderate (2) or severe (3).

\section{Statistics}

The results are expressed as means and standard deviations. The data concerning diet, SCFA and blood lipids were analysed by paired Student's $t$ test for significance.

Before statistical analysis of the bacteriological data the cell counts were transformed to $\log _{10}$ numbers. Effects of diet on bacteriological numbers were tested by ANOVA and by the non-parametric Kruskal-Wallis test (for small numbers of observations). The data collected over time were analysed as a repeated measurement in time using Friedman and Dunn-Rankin tests (Wilcoxon \& Wilcox, 1964). The significance of gastrointestinal symptoms was assessed by comparing symptoms experienced in the run-in and intervention phases of the inulin period using the Wilcoxon test. In each case, differences were considered to be significant at $P<0.05$.

\section{Results \\ General}

Initially, eleven volunteers participated in the study, but only eight finished the intervention phase of inulin administration. Two subjects dropped out of the group because of gastrointestinal discomfort. Another subject became ill, but the illness was not related to the inulin administered. For all remaining subjects $(n 8)$ complete data sets were collected, and these were interpreted. The same subjects were recruited for the control study.

\section{Energy requirement and macronutrient proportions}

Tables 1 and 2 give the average energy intakes and macronutrient proportions during the two phases of the study, covering both the controlled part and the free-living part of the study. The latter comprised food intake in the evenings and at the weekends. The results show that the subjects' food intakes followed exactly the study plan: in the run-in phase $44 \%$ of the energy was provided in the form of fat; this proportion changed to $30.4 \%$ in the intervention phase.

\section{Blood lipids}

Blood lipid concentrations of the subjects are shown in Table 3. Results demonstrate individual differences. No significant changes were observed during inulin treatment.

\section{Faecal microflora}

The analysis of faecal bacterial counts revealed a significant increase in the number of bifidobacteria by about 1 log after ingestion of inulin compared with the corresponding run-in period (Fig. 1). The follow-up period ( $34 \mathrm{~d}$ following the end of the study) under a normal everyday diet without inulin and restrictions to the macronutrient proportions resulted in a decrease in bifidobacteria to $10.3 \log _{10} / \mathrm{g}$ dry faeces. In contrast, there were no differences in the number 
Table 1. Energy intakes $(\mathrm{kJ} / \mathrm{d})$ of subjects consuming a control diet or a diet containing inulin during run-in and intervention phases of the study*

(Mean values and standard deviations for eight subjects)

\begin{tabular}{|c|c|c|c|c|c|c|}
\hline \multirow[b]{2}{*}{ Phase of study } & \multicolumn{3}{|c|}{ Control } & \multicolumn{3}{|c|}{ Inulin } \\
\hline & Mean & SD & $\Delta \S(\%)$ & Mean & SD & $\Delta \S(\%)$ \\
\hline \multicolumn{7}{|l|}{ Run-in (high-fat) $\dagger$} \\
\hline Maintenance energy & 9629 & 1726 & & 9629 & 1726 & \\
\hline Energy intake & 9670 & 1529 & & 9394 & 2191 & \\
\hline \multicolumn{7}{|l|}{ Intervention (low-fat)‡ } \\
\hline Maintenance energy & 9629 & & & & & \\
\hline \multirow{2}{*}{ Energy intake } & 9117 & 1768 & & 9448 & 1500 & \\
\hline & & & $-5 \cdot 3$ & & & -1.9 \\
\hline
\end{tabular}

* For details of diets and procedures, see p. 376.

†Average of energy intake of $8 d, 45 \%$ energy as fat, $40 \%$ energy as carbohydrate.

$\ddagger$ Average of energy intake of $64 \mathrm{~d}, 30 \%$ energy as fat, $55 \%$ energy as carbohydrate.

$\S$ Maintenance energy $=100 \%$.

of total bacteria. Bacterial counts of control subjects remained unchanged throughout all study periods and were on average 11.0 (SD 0.4 ) $\log _{10} / \mathrm{g}$ for total organisms, and 9.7 (SD 0.5$) \log _{10} / \mathrm{g}$ for bifidobacteria.

\section{Short-chain fatty acids}

Parallel to microbiological tests stool samples were analysed for SCFA (Table 4). The results show great interindividual differences. SCFA were not significantly different between the phases of low-fat intervention (inulin and control).

\section{Assessment of gastrointestinal symptoms}

Regarding the evaluation of gastrointestinal symptoms as a result of inulin administration, subjects generally observed signals of discomfort (Table 5). However, these were interpreted individually in different ways. Flatulence and bloatedness were the most common complaints associated with the inulin intervention phase, but they were ranked mild (1) to moderate (2). The consistency of stool was

Table 2. Proportions of fat, carbohydrate and protein (\% energy) in the food of subjects consuming a control diet or a diet containing inulin during run-in and intervention phases of the study*

(Mean values and standard deviations for eight subjects)

\begin{tabular}{llllll}
\hline & \multicolumn{2}{c}{ Control } & & \multicolumn{2}{c}{ Inulin } \\
\cline { 2 - 3 } \cline { 5 - 6 } & Mean & SD & & Mean & SD \\
\hline Run-in (high-fat) $\dagger$ & 44.0 & 2.4 & & 44.1 & 2.1 \\
$\quad$ Fat & 42.3 & 2.6 & & 42.0 & 1.9 \\
$\quad$ Carbohydrate & 13.7 & 1.3 & & 13.9 & 1.1 \\
$\quad \begin{array}{l}\text { Protein } \\
\text { Intervention (low-fat) } \neq\end{array}$ & & & & \\
$\quad$ Fat & 30.4 & 1.5 & & 30.6 & 1.4 \\
$\quad$ Carbohydrate & 54.7 & 1.9 & & 54.9 & 1.9 \\
$\quad$ Protein & 14.9 & 1.2 & & 14.5 & 0.8 \\
\hline
\end{tabular}

For details of diets and procedures, see p. 376.

† Average of energy intake of $8 \mathrm{~d}, 45 \%$ energy as fat, $40 \%$ energy as carbohydrate.

$\ddagger$ Average of energy intake of $64 \mathrm{~d}, 30 \%$ energy as fat, $55 \%$ energy as carbohydrate. reported to be essentially unchanged and within the normal range of day-to-day fluctuations. There were no complaints about diarrhoea, nausea or other side-effects in response to inulin administration. The participants in the study also reported that flatulence and bloatedness, which occurred in the first 2 weeks after the onset of inulin intake, improved within 2-4 weeks thereafter. However, there was still a significant difference in these symptoms between run-in and intervention phases. Symptoms of discomfort disappeared immediately on discontinuation of inulin consumption.

\section{Discussion}

The partial replacement of dietary fat by inulin in an otherwise isoenergetic diet which was consumed by eight subjects for a period of $64 \mathrm{~d}$ distinctly promoted the growth of bifidobacteria. The administration of inulin did not affect any of the following variables significantly: total cholesterol, HDL, LDL and triacylglycerols in serum, total faecal SCFA, molar ratios of faecal SCFA.

Considerable efforts have been made to manipulate the composition of the intestinal microflora in such a way that colonization of the gut by potential pathogenic organisms and production of toxic bacterial metabolites is suppressed (Roland, 1988; Gibson \& Roberfroid, 1995). One strategy of microbial flora manipulation is based on the consumption of particular food ingredients such as oligofructose or inulin, which become available for microbial fermentation by potentially health-promoting bacteria such as Bifidobacterium and Lactobacillus (Gibson et al. 1995; Kleessen et al. 1997).

Recent advances in molecular biology have made it possible to enumerate bacterial populations without prior cultivation. The results obtained with these methods give a more realistic picture of the composition of the intestinal microflora (Welling et al. 1997). Using 16S rRNA targeted oligonucleotide probes that either detect all bacteria (EUB mix) or bifidobacteria (BIF 164) we studied the long-term effects of inulin on faecal flora. The bifidogenic effect of inulin observed in our study agrees with 
Table 3. Fasting blood lipid concentrations $(\mathrm{mmol} / \mathrm{l})$ of subjects consuming a control diet or a diet containing inulin at the end of the run-in period and on day 27 and at the end of the intervention period*

(Mean values and standard deviations for eight subjects)

\begin{tabular}{|c|c|c|c|c|c|c|c|c|c|c|c|c|}
\hline & \multicolumn{6}{|c|}{ Inulin } & \multicolumn{6}{|c|}{ Control } \\
\hline & Mean & SD & Mean & SD & Mean & $\mathrm{SD}$ & Mean & $\mathrm{SD}$ & Mean & SD & Mean & SD \\
\hline Total cholesterol & 5.5 & 0.7 & 5.2 & 0.6 & 5.0 & 0.5 & $5 \cdot 8$ & 0.8 & 5.4 & 0.7 & $5 \cdot 3$ & 0.8 \\
\hline LDL:HDL & $2 \cdot 9$ & 0.6 & $2 \cdot 9$ & 0.7 & 3.0 & 0.8 & 3.4 & 0.6 & 3.4 & 0.5 & 3.3 & 0.3 \\
\hline Triacylglycerols & 1.0 & 0.3 & $1 \cdot 1$ & 0.3 & 1.2 & 0.3 & 1.0 & 0.3 & 1.1 & 0.4 & 1.2 & 0.2 \\
\hline
\end{tabular}

${ }^{*}$ For details of diets and procedures, see p. 376.

previous findings of in vitro (Gibson \& Roberfroid, 1995) and in vivo studies (Gibson et al. 1995; Bouhnik et al. 1996; Buddington et al. 1996; Kleessen et al. 1997) in which oligofructose, galactooligosaccharides and inulin were used as non-digestible carbohydrates.

One important finding of the study concerns the decrease in bifidobacteria in the time following dietary intervention (Fig. 1). Since the bifidobacteria increased during the consumption of inulin and total organisms remained constant it has to be concluded that other intestinal organisms such as Bacteroides, clostridia or coliforms decreased in number (Kleessen et al. 1997). The increase in bifidobacteria in the intestine may contribute to the stabilization of the microflora and to the health of the host (Fuller, 1991; Gibson \& Wang, 1994). Future studies are needed to unravel the exact mechanisms underlying the claimed health-promoting effects of bifidobacteria.

Blood lipids were essentially unaffected. This may be due to the fact that participants of the study were healthy and cholesterol levels were in the normal range. This does not necessarily mean that inulin is not effective in lowering blood lipids in healthy individuals. Data from other human studies are contradictory (Taylor \& Williams, 1998). One study reported a $27 \%$ reduction in triacylglycerol at a dose of $9 \mathrm{~g}$ inulin/d on a cereal breakfast (Canzi et al. 1996). This result is surprising, since high-carbohydrate diets commonly increase the levels of triacylglycerol caused by the stimulated hepatic VLDL formation (Coulston et al. 1983). On the other hand, studies by Luo et al. (1996) and Pedersen et al. (1997) which were similar to the one presented here showed no alterations in blood lipids. It is conceivable that effects can be observed only in hyperlipidaemic patients as reported for diabetics (Yamashita et al. 1984; Hidaka et al. 1991). However, Davidson et al. (1998) reported only small declines of cholesterol levels among hypercholesterolaemic subjects after a 6-week treatment with inulin. Alterations in

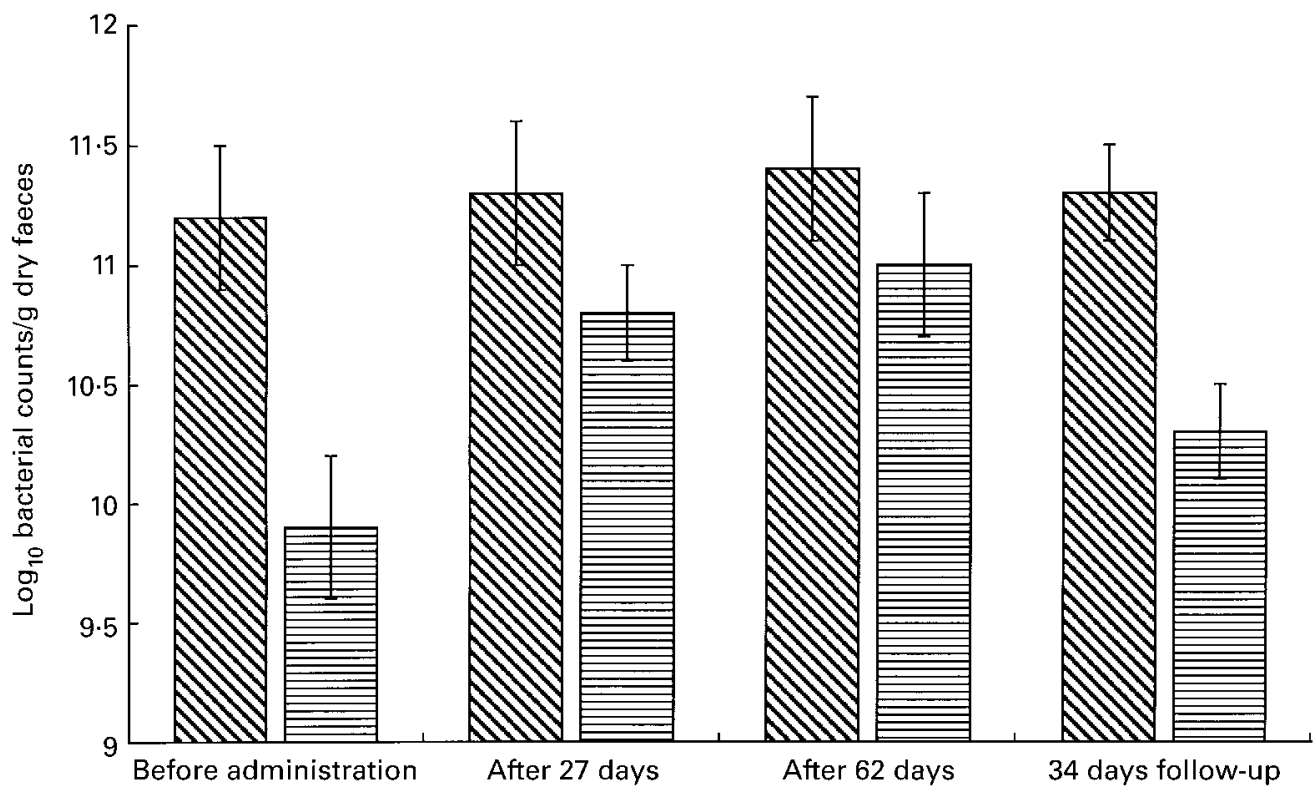

Fig. 1. Development of bifidobacteria (目) and total bacterial counts $(\mathbb{\nabla})$ with time in subjects consuming a diet containing inulin. Values are means for eleven subjects with their standard deviations represented by vertical bars. 
Table 4. Concentrations of short-chain fatty acids (SCFA; $\mu \mathrm{mol} / \mathrm{g}$ dry faeces) in the stools of subjects consuming a control diet or a diet containing inulin at different stages during the run-in and intervention periods*

(Mean values and standard deviations for eight subjects)

\begin{tabular}{|c|c|c|c|c|c|c|c|c|c|c|c|c|}
\hline \multirow[b]{2}{*}{ SCFA† } & \multicolumn{8}{|c|}{ Inulin } & \multicolumn{4}{|c|}{ Control } \\
\hline & Mean & SD & Mean & SD & Mean & SD & Mean & SD & Mean & SD & Mean & SD \\
\hline Acetate & 168.4 & $101 \cdot 1$ & 198.9 & 104.7 & 209.9 & $54 \cdot 4$ & 205.4 & 88.4 & $140 \cdot 8$ & 59.4 & 99.0 & 39.1 \\
\hline
\end{tabular}

${ }^{*}$ For details of diets and procedures, see p. 376.

† Two preparations were separately analysed by GC and than averaged.

$\$ 34 \mathrm{~d}$ following the end of the study under normal life conditions.

blood lipid concentrations as indicated in animal studies (Delzenne et al. 1993; Roberfroid, 1993) were not found.

The bifidogenic effect of inulin was not accompanied by distinct changes in faecal SCFA (Table 4). The data collected in the present study were highly variable, demonstrating interindividual differences, and in accordance with a short-term study with enterally fed patients (Sobotka et al. 1997) in which alterations in faecal SCFA concentrations could not be observed. In contrast to the results presented here, a clinical study with elderly patients (Kleessen et al. 1997) showed slight changes in the relative proportions of acetate and butyrate. The amounts of inulin applied in these studies were in the same range.

An intensification of gastrointestinal symptoms was only observed during inulin intake. The questionnaire filled in by the participants of the study indicated that the consumption of inulin caused a number of undesirable gastrointestinal symptoms. Nine out of eleven categories describing these symptoms were marked by the subjects. Two of these categories (nausea and vomiting) were not reported by any of the participants. Flatulence and bloatedness were the major symptoms reported. These culminated $8-9 \mathrm{~h}$ after the inulin intake. The formation of $\mathrm{H}_{2}$, which is a by-product of bacterial fermentation in the colon, is most probably the major cause of these symptoms. However, it has to be emphasized that bifidobacteria are not capable of $\mathrm{H}_{2}$ formation.

Subjects confirmed that the discomfort experienced was acceptable and that the symptoms perceived during intervention did not change. The variation in the subjects' responses may be due to individually different experience related to dietary habits; i.e. individual differences in the consumption of non-digestible carbohydrates. Because subjects were interviewed at the end of both the run-in and the intervention phases, statements of subjects may also reflect adaptation to inulin. This appears to be reasonable because it can be expected that the colonic flora which may be partly responsible for effects of discomfort required some time to adapt to inulin as the major substrate. The results of Pedersen et al. (1997) are in contrast to the data presented here. With the application of nearly the half of the inulin dose used in this study, Pedersen et al. (1997) noted no adaptation of subjects to inulin.

The statements of the participants are of particular importance with respect to the use of inulin or fructooligosaccharides as a food supplement in everyday life, because in the present study the long-term effect was studied.

In summary, the data indicate that a high-dose long-term application of inulin is practicable. Alteration of the colonic microbiota in favour of bifidobacteria was a clear effect of

Table 5. Gastrointestinal symptoms and degree of discomfort after administration of inulin expressed as frequencies of scores of eight subjects $\dagger$

(Ranking: 0, absent; 1, mild; 2, moderate; 3, severe)

\begin{tabular}{|c|c|c|c|c|c|c|c|c|c|}
\hline \multirow[b]{2}{*}{ Degree of discomfort... } & \multicolumn{4}{|c|}{ Run-in $\ddagger$} & \multicolumn{4}{|c|}{ Intervention§ } & \multirow[b]{2}{*}{ Difference } \\
\hline & $(0)$ & $(1)$ & $(2)$ & (3) & $(0)$ & $(1)$ & (2) & (3) & \\
\hline Flatulence & 4 & 4 & & & 1 & & 4 & 3 & * \\
\hline Bloatedness & 5 & 3 & & & 2 & 1 & 4 & 1 & * \\
\hline Diarrhoea & 7 & 1 & & & 3 & 4 & & 1 & * \\
\hline Rumbling of stomach & 7 & 1 & & & 5 & 2 & & 1 & \\
\hline Rumbling in the gut & 6 & 2 & & & 0 & 2 & 2 & 1 & * \\
\hline Cramps of stomach & 8 & & & & 5 & 2 & & 1 & \\
\hline Cramps of gut & 8 & & & & 5 & 1 & 1 & 1 & \\
\hline
\end{tabular}

Differences between the groups were significant: ${ }^{*} P<0.05$.

†For details of diet and procedures, see p. 376.

$\mp$ The interview was conducted at the end of an $8 \mathrm{~d}$ period

$\S$ The interview was conducted at the end of a $64 \mathrm{~d}$ period. 
inulin administration. Since the majority of participants in the study did not feel significantly affected by symptoms of discomfort, inulin can be expected to be a useful fat replacer supporting weight reduction of excess weight. While there were no effects on blood lipids, future studies have to find out whether inulin administration may influence other physiological variables such as food intake and satiety perception.

\section{Acknowledgements}

We are indebted to Yvonne Paeben for her contribution to this study. We are especially grateful to our study participants for their cooperation. This work was supported by European Research Project Fair-CT-97-3035 and by the FEI (Forschungskreis der Ernährungsindustrie e.V., Bonn), the AiF and the Ministry of Economics. Project no.: 10326 B.

\section{References}

Amann RI, Ludwig W \& Schleifer K-H (1995) Phylogenetic identification and in situ detection of individual microbial cells without cultivation. Microbiological Reviews 59, 143-169.

Bouhnik Y, Flourie B, Andrieux C, Bisetti N, Briet F \& Rambaud J-C (1996) Effects of Bifidobacterium sp fermented milk ingested with or without inulin on colonic bifidobacteria and enzymatic activities in healthy humans. European Journal of Clinical Nutrition 50, 269-273.

Bruhn CM, Cotter A, Diaz-Knauf K, Sutherlin J, West E, Wightman N, Williamson E \& Yaffee M (1992) Consumer attitudes and market potential for foods using fat substitutes. Food Technology 46, 81-86.

Buddington RK, Williams CH, Chen S-C \& Whiherly SA (1996) Dietary supplements of neosugar alters the fecal flora and decreases activities of some reductive enzymes in human subjects. American Journal of Clinical Nutrition 63, 709-716.

Canzi E, Brighenti F, Casiraghi MC, Del Puppo E \& Ferrari A (1996) Prolonged consumption of inulin in ready-to-eat breakfast cereals: effects on intestinal ecosystem, bowel habits and lipid metabolism. In Proceedings of the COST Action 92 'Dietary Fiber and Fermentation in the Colon', Espoo, Finland, 15-17 June 1995, pp. 280-284 [Y Mälkki and JH Cummings, editors]. Brussels: European Commission, Directorate-General XII, Science, Research and Development.

Coulston AM, Liu GC \& Reaven GM (1983) Plasma glucose, insulin and lipid responses to high-carbohydrate low-fat diets in normal humans. Metabolism 32, 52-56.

Cummings JH (1981) Short-chain fatty acids in the human colon. Gut 22, 763-779.

Cummings JH \& MacFarlane GT (1997) Role of intestinal bacteria in nutrient metabolism. Clinical Nutrition 16, 3-11.

Davidson MH, Maki KC, Synecki C, Torri SA \& Drennan KB (1998) Effects of dietary inulin on serum lipids in men and women with hypercholesterolemia. Nutrition Research 18, 503-517.

Delzenne NM, Kok N, Fiordaliso M-F, Deboyser DM, Goethals FM \& Roberfroid MB (1993) Dietary fructo-oligosaccharides modify lipid metabolism in rats. American Journal of Clinical Nutrition 57, 820S.

Dreon DM, Frey-Hewitt B, Ellsworth N, Williams PT, Terry RB \& Wood PD (1988) Dietary fat: carbohydrate ratio and obesity in middle aged men. American Journal of Clinical Nutrition 47, 995-1000.

Erbersdobler H, Petry H \& Tiews J (1976) Energiehaushalt (Energy balance). In Lehrbuch der Veterinär-Physiologie, 6th ed., pp. 325362 [A Scheunert and A Trautmann, editors]. Berlin: PareyVerlag.
Fuller R (1991) Probiotics in medicine. Gut 32, 439-442.

Gibson GR, Beatty ER, Wang X \& Cummings JH (1995) Selective stimulation of bifidobacteria in the human colon by oligofructose and inulin. Gastroenterology 108, 975-982.

Gibson GR \& Roberfroid MB (1995) Dietary modulation of the human colonic microbiota: introducing the concept of prebiotics. Journal of Nutrition 125, 1401-1412.

Gibson GR \& Wang X (1994) Regulatory effects of bifidobacteria on other colonic bacteria. Journal of Applied Bacteriology 77, 412-420.

Grundy SM (1991) Recent nutrition research: implications for foods of the future. Annals of Medicine 23, 187-193.

Hautvast J (1992) Nutrition in the nineties: an overall view. In Human Nutrition. A Continuing Debate, pp. 218-231 [M Eastwood, C Edwards and D Parry, editors]. London, New York, Tokyo, Melbourne, Madras: Chapman \& Hall.

Hidaka H, Tashiro Y \& Eida T (1991) Proliferation of bifidobacteria by oligosaccharides and their useful effect on human health. Bifidobacteria Microflora 10, 65-79.

Kleessen B, Sykura B, Zunft H-J \& Blaut M (1997) Effects of inulin and lactose on fecal microflora, microbial activity, and bowel habit in elderly constipated persons. American Journal of Clinical Nutrition 65, 1397-1402.

Klesges RC, Klesges LM, Haddock CK \& Eck LH (1992) A longitudinal analysis of the impact of dietary intake and physical activity on weight change in adults. American Journal of Clinical Nutrition 55, 818-822.

Langendijk PS, Schut F, Jansen GJ, Raangs GC, Kamphuis GR, Wilkinson MHF \& Welling GW (1995) Quantitative fluorescence in situ hybridization of Bifidobacterium spp. with genusspecific 16S rRNA-targeted probes and its application in fecal samples. Applied Environmental Microbiology 61, 3069-3075.

Luo J, Rizkalla SW, Alamowitch C, Boussairi A, Blayo A, Barry JL, Lafitte A, Guyon F, Bornet FRJ \& Slama G (1996) Chronic consumption of short-chain fructooligosaccharides by healthy subjects decreased basal hepatic glucose production but had no effects on inulin-stimulated glucose metabolism. American Journal of Clinical Nutrition 63, 939-945.

Manz W, Szewzyk U, Eriksson P, Amann R, Schleifer K-H \& Stenström T-A (1993) In situ identification of bacteria in drinking water and adjoining biofilms by hybridization with $16 \mathrm{~S}$ and $23 \mathrm{~S}$ rRNA-directed fluorescent oligonucleotide probes. Applied Environmental Microbiology 59, 2293-2298.

Pedersen A, Sandström B \& van Amselvoort JMM (1997) The effect of ingestion of inulin on blood lipids and gastrointestinal symptoms in healthy females. British Journal of Nutrition 78, 215-222.

Pomare EW, Branch WJ \& Cummings JH (1985) Carbohydrate fermentation in the human colon and its relation to acetate concentrations in venous blood. Journal of Clinical Investigation 75, $1448-1454$.

Roberfroid MB (1993) Dietary fiber, inulin and oligofructose: a review comparing their physiological effects. Critical Reviews in Food Science and Nutrition 33, 102-148.

Roberfroid MB, Gibson GR \& Delzenne N (1993) The biochemistry of oligofructose, a nondigestible fibre: an approach to calculate its caloric value. Nutrition Reviews 51, 137-146.

Roberfroid MB, Van Loo JAE \& Gibson GR (1998) The bifidogenic nature of chicory inulin and its hydrolysis products. Journal of Nutrition 128, 11-19.

Roediger WEW (1980) Role of anaerobic bacteria in the metabolic welfare of the colonic mucosa in man. Gut 21, 793-798.

Roland IR (1988) Factors affecting metabolic activity of the intestinal microflora. Drug Metabolism Reviews 19, 243-261.

Scheppach W (1994) Effects of short chain fatty acids on gut morphology and function. Gut 35, S35-S38.

Scheppach WM, Fabian CE \& Kasper HW (1987) Fecal 
short-chain fatty acid (SCFA) analysis by capillary gasliquid chromatography. American Journal of Clinical Nutrition 46, 641-646.

Scheppach W, Sachs M, Bartram P \& Kasper H (1989) Faecal short-chain fatty acids after colonic surgery. European Journal of Clinical Nutrition 43, 21-25.

Silva RF (1996) Use of inulin as a natural texture modifier. Cereal Foods World 41, 792-794.

Sobotka L, Bratova M, Slemrova M, Manak J, Vizda J \& Zadak Z (1997) Inulin as the soluble fiber in liquid enteral nutrition. Nutrition 13, 21-25.

Steiniger J, Karst H, Noack R \& Steglich H-D (1987) Diet-induced thermogenesis in man: thermic effects of single protein and carbohydrate test meals in lean and obese subjects. Annals of Nutrition and Metabolism 31, 117-125.

Taylor GRJ \& Williams CM (1998) Effects of probiotics and prebiotics on blood lipids. British Journal of Nutrition 80, S225-S230.

Van Munster IP, de Boer HM, Jansen MC, de Haan AE, Katan MB, van Amselvoort JM \& Nagengast FM (1994) Effect of resistant starch on breath-hydrogen and methane excretion in healthy volunteers. American Journal of Clinical Nutrition 59, 626630.

Wang X \& Gibson GR (1993) Effect of the in vitro fermentation of oligofructose and inulin by bacteria growing in the human large intestine. Journal of Applied Bacteriology 75, 373-380.

Watts GF, Lewis B, Brunt JNH, Lewis ES, Coltart DJ, Smith LDR, Mann JI \& Swan AV (1992) Effects on coronary artery disease of lipid-lowering diet, or diet plus cholestyramine, in the St Thomas' Atherosclerosis Regression Study (STARS). Lancet 339, 563-569.

Welling GW, Elfferich P, Raangs GC, Wildeboer-Veloo ACM, Jansen GJ \& Degener JE (1997) 16S Ribosomal rRNA-targeted oligonucleotide probes for monitoring of intestinal tract bacteria. Scandinavian Journal of Gastroenterology 32, Suppl. 222, 17-19.

Wilcoxon F \& Wilcox RA (1964) Some Rapid Approximate Statistical Procedures. New York, NY: Lederle Laboratories.

World Health Organization (1985) Energy and Protein Requirements. Technical Report Series no. 724. Geneva: WHO.

Yamashita K, Kawai K \& Itakura M (1984) Effects of fructooligosaccharides on blood glucose and serum lipids in diabetic subjects. Nutrition Research 4, 961-966. 